Check for updates

Cite this: RSC Adv., 2017, 7, 36246

Received 23rd May 2017

Accepted 3rd July 2017

DOI: $10.1039 / \mathrm{c} 7 \mathrm{ra05797k}$

rsc.li/rsc-advances

\section{An efficient strategy for full mineralization of an azo dye in wastewater: a synergistic combination of solar thermo- and electrochemistry plus photocatalysis}

\author{
Chunhong Nie, Jing Dong, Pingping Sun, Chao Yan, Hongjun Wu \\ and Baohui Wang (D)
}

\begin{abstract}
Herein, a synergistic combination of three flows, i.e. photo-flow, thermo-flow, and electro-flow, from solar energy was first constructed and then utilized for the mineralization of an azo dye in wastewater. Taking methyl orange as an example, the mineralization of the azo dye was theoretically and experimentally investigated. The results indicated that the oxidation efficiency of the photo-electro-thermo flows could reach up to $81.88 \%$ within 60 min, which was superior to those of the corresponding single flow or two flows, and full mineralization to $\mathrm{CO}_{2}$ was realized. The mechanism of mineralization was discussed by comparing the molecular conjugate chain detected by UV and the intermediate products identified by HPLC and GC. Non-linear regression was used to obtain the rate equation of methyl orange mineralization. A significant synergetic effect of solar thermo- and electrochemistry plus photocatalysis was observed. The evidence shows that the synergistic application of three flows from solar energy can greatly provide an effective way for the enhancement of the utilization of solar energy and the oxidation of azo dye pollutants.
\end{abstract}

\section{Introduction}

Water pollution by synthetic organic dyes has been a critical issue in maintaining good water quality. ${ }^{1,2}$ As reported, more than 100000 commercial dyes are available with an estimated annual output of $7 \times 10^{5}$ tons, ${ }^{3}$ and they are usually present at high concentrations in large volumes of wastewater. ${ }^{4}$ Azo dyes are widely used in printing and dyeing industries due to high stability of the azo groups. ${ }^{5,6}$ This is the main dye species in wastewater discharge. Azo dyes are very stable and not easily oxidized and degraded. If non-degradable organic pollutants in the wastewater are discharged into water, the pollutants will consume the dissolved oxygen in the water. ${ }^{7-9}$ This will destroy the ecological balance of the water body and cause serious threat to the survival of fish and other aquatic organisms. ${ }^{10,11}$

Many studies have reported traditional and advanced methods, such as biological and chemical methods involving electrochemical methods and advanced oxidation processes (AOPs), for the removal of dyes in water..$^{3-6,12-14}$ Biological methods are commonly used for the treatment of dye wastewater due to the special capabilities of microorganisms to degrade dyes. Moreover, biological methods are effective,

Institute of New Energy Chemistry and Environmental Science, College of Chemistry and Chemical Engineering, Northeast Petroleum University, Daqing, 163318, China. E-mail:wangbh@nepu.edu.cn environmentally friendly, and relatively inexpensive. However, the application of biological methods is limited because of the characteristics of the large area, poor anti-poisoning, and longterm. ${ }^{13}$ Moreover, biological methods fail to mineralize the dye groups. $^{15}$

Traditional chemical methods usually require the addition of new chemical reagents, which cause secondary pollution. ${ }^{16}$ Therefore, these methods were constrained by the environmental protection requirements. Advanced oxidation processes (AOPs) have been successfully applied for the treatment of wastewater ${ }^{17-22}$ due to the fact that the hydroxyl radical $(\cdot \mathrm{OH})$ generated in AOPs can non-selectively oxidize most organic pollution. ${ }^{23-26}$ However, the application of AOPs is currently not accepted because of expensive investment and operational problems. ${ }^{3,4,12}$

Electrochemical technology has been widely investigated for the prevention and remediation of pollution because electrons are clean reagents. However, due to the lack of applicability of industrial technology, few researchers have shown interest in electrochemical technologies for the treatment of dye wastewater before the year $2000 .^{3}$ In recent years, electrochemical advanced oxidation processes (EAOPs) have attracted significant attention, which not only contribute to the treatment of wastewater but also contribute to process-integrated environmental protection. Compared to the traditional AOPs, in EAOPs, heterogeneous ${ }^{\circ} \mathrm{OH}$ is formed at the anode surface and the 
pollutants are oxidized in an electrolytic cell. The main drawback of EAOPs is electric energy consumption.

Solar energy has been recognized as a clean and permanent energy resource, and new conversion systems have been constructed for solar energy utilization. In our past studies, solar STEP-AOPs (solar thermal electrochemical process-AOPs) of organic pollutants have been successfully demonstrated to be efficient for the treatment of organic wastewater. ${ }^{27-33}$ STEP-AOPs are driven by solar thermo-flow and solar electro-flow, essentially the combination of thermochemistry with electrochemistry. In order to have a rich harvest of solar energy for a treatment of wastewaters, the synergistic application of three flows, i.e. photo-flow, thermo-flow, and electro-flow, from the sun was considered to greatly provide an effective way for enhancement of the utilization of solar energy and the oxidation of organic pollutants. In this study, we first constructed a synergistic combination of three flows from solar energy and then utilized the STEP-AOP system for full mineralization of azo dyes in wastewater in a pattern of solar thermo-electrochemistry plus photocatalysis. Taking methyl orange as an example, the full mineralization of azo dyes driven by a synergistic combination of the three flows from the sun was theoretically and experimentally investigated. The purpose of this study was how to make full use of the coordinated effects between photo-, electro-, and thermo-flow from solar energy for specific molecular oxidation, such that to increase the oxidation efficiency of contaminants and improve the utilization efficiency of solar energy.

\section{Methods and materials}

\subsection{Chemicals and materials}

Methyl orange $\left(\mathrm{C}_{14} \mathrm{H}_{14} \mathrm{~N}_{3} \mathrm{SO}_{3} \mathrm{Na}\right.$, A.R $)$ was received from Shanghai Chemical. Platinum foil (99.95\% purity) was purchased from ADHS Company of Tianjin. Maleic acid, benzenediol, hydroquinone, formic acid, and sodium sulfate were used as received from Beijing Chemical.

\subsection{Experiments of a synergistic combination of three flow STEP-AOPs for full mineralization of the azo dye}

2.2.1 Experimental setup. Synergistic combinations of three-flow STEP-AOPs from solar energy, i.e. photo-flow, thermo-flow, and electro-flow, were constructed. The devices were composed of three parts: solar heat utilization system, solar photovoltaic conversion system, and a reactor containing $\mathrm{TiO}_{2}$. The parameters of the device were optimized through numerical simulation. For experiments of different combination modes such as single flow or two flows, the devices were composed of the corresponding parts. As shown in Fig. 1, the solar energy heat utilization system is mainly composed of a heat collector with a parabolic concentrator ( $\Phi 1.5 \mathrm{M}, \mathrm{Max}$.$) ,$ a hot water tank, and a pipeline that provides cold water and hot water. The solar photovoltaic unit is a commercial silicon PV panel with a capacity of $1500000 \mathrm{~mA} \mathrm{~h}\left(V_{\max }=5 \mathrm{~V}, I_{\mathrm{sc}}=1 \mathrm{~A}\right.$ and an active surface area $=40 \mathrm{~cm}^{2}$ ). The reactor has an undivided cylindrical configuration, which can be controlled at some

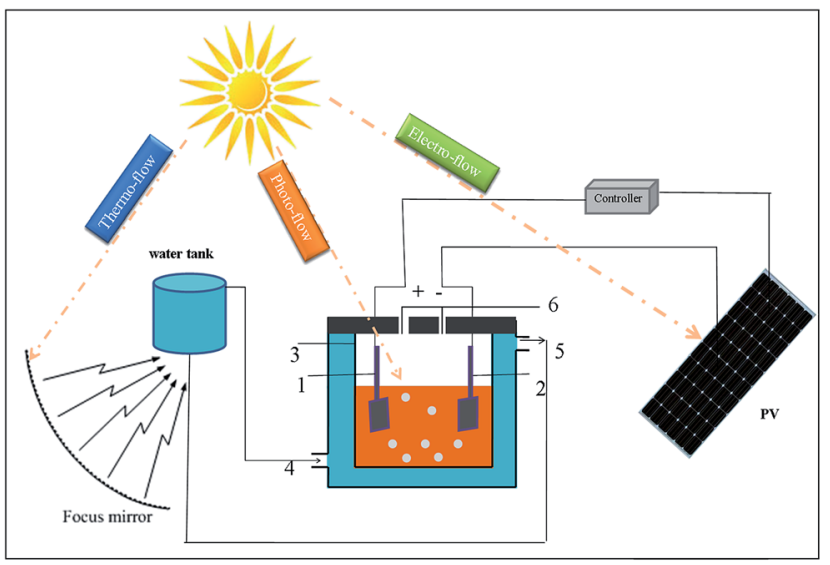

Fig. 1 Schematic of the solar three-flow-driven STEP-AOP mineralization of dye. (1) Pt anode; (2) Pt cathode; (3) reaction vessel; (4) hot water inlet; (5) hot water outlet; and (6) gas outlet.

temperature by adjusting the flow velocity of the cold and hot water. The electrolysis under constant pressure or constant current is realized by adding the controller into the circuit. The cell consisted of a conventional three-electrode system: a $2 \mathrm{~cm}$ $\times 2 \mathrm{~cm}$ platinum sheet as the working electrode, a $2 \mathrm{~cm} \times 2 \mathrm{~cm}$ platinum sheet as the counter electrode, and a reference electrode of saturated $\mathrm{Ag} / \mathrm{AgCl}$; gap between the electrodes was $2.5 \mathrm{~cm}$. For a test, $100 \mathrm{~mL}$ of azo dye solution $\left(100 \mathrm{mg} \mathrm{L}^{-1}\right)$ with $\mathrm{pH}=3$ was stirred for $60 \mathrm{~min}$ with $5 \mathrm{~g} \mathrm{~L}^{-1}$ sodium sulfate as the electrolyte.

2.2.2 Analysis of the products and intermediates. Methyl orange, intermediates, and products were monitored using high-performance liquid chromatography (LC-2010A HT) with a $\mathrm{C} 18$ reverse separation column $(150 \times 4.60 \mathrm{~mm})$. The flow rate was $0.8 \mathrm{~mL} \mathrm{~min}{ }^{-1}$ and the column temperature was $25^{\circ} \mathrm{C}$. A sample of $20 \mu \mathrm{L}$ was injected into HPLC with methanol/water (v/ $\mathrm{v}=3: 1$ ) as the mobile phase. The UV wavelength of the detector was set at $254 \mathrm{~nm}$. Methyl orange, intermediates, and products were identified by retention times when compared with those of the pure standards.

Ultraviolet-visible spectra were obtained using a UV-1700 (SHIMADZU) with a wavelength of $464 \mathrm{~nm}$. The luminescence spectra were obtained by Perkin Elmer LS-55.

\section{Results and discussion}

For the treatment of organic wastewater, solar energy can be utilized in three ways. The solar radiations of infrared region ( $43 \%$ of solar energy) can be collected as heat energy that can be supplied to the reaction; the solar radiations of visible region ( $50 \%$ of solar energy) can be collected and converted to electricity by photovoltaic cells that can be suppled to the reaction; the solar radiations of ultraviolet region ( $7 \%$ of solar energy) can be directly utilized to treat organic wastewater via the addition of an appropriate photocatalyst. ${ }^{34,35}$ Thus, solar energy provides three effects, i.e. photo, electro, and thermo, for the treatment of organic wastewater, which are defined as photo-flow, electroflow, and thermo-flow, respectively. In our past studies, the 
combination of solar thermo-flow and solar electro-flow, i.e. STEP-AOPs, displayed an efficient approach to the treatment of organic wastewater, essentially through the combination of thermochemistry with electrochemistry. This method is governed by solar thermo-electrochemistry of STEP-AOPs. In this study, the synergistic application of three flows was considered to greatly provide an effective way for enhancement of the utilization of solar energy and the oxidation of organic pollutants. With the relevant application of three flows, the process can be described by solar thermo-electrochemistry plus photocatalysis of the STEP-AOPs, named as three-flow STEP-AOPs.

In the theory of three-flow STEP-AOPs, the application of three flows not only results in higher solar conversion efficiency but also results in a higher oxidation efficiency of the organic pollutants that are attributed to the synergy of the three flows. The heat from solar energy is initially used to activate organics or directly destroy molecules; this is a characteristic of thermochemical reactions. Then, the activated organics are decolorized (a decolorization step) and oxidized into small molecules (a degradation step). Finally, full mineralization to $\mathrm{CO}_{2}$ (a mineralization step) is achieved by either electrochemical and photocatalytic reaction or their combination. The thermoelectrochemistry plus photocatalysis tunes photo-flow, electroflow, and thermo-flow to match the oxidation of specific organic pollutants.

The energy levels of single flow, two flows, and three flows are shown in Fig. 2. It is obvious that the joint application of three flows is highly advantageous.

\subsection{Action of the single flow for the STEP-AOP mineralization of dye}

Fig. 3 shows the measured reaction of azo dye oxidation under solar thermo-flow. As shown in Fig. 3, the variation in concentration is not significant, which indicates that oxidation efficiency under the solar thermo-flow is low.

Here we raise the question of whether the heat has no effect on the oxidation of methyl orange. For further verification, we obtained the fluorescence spectra of the solution system; the results are shown in Fig. 4. The fluorescence emission peaks

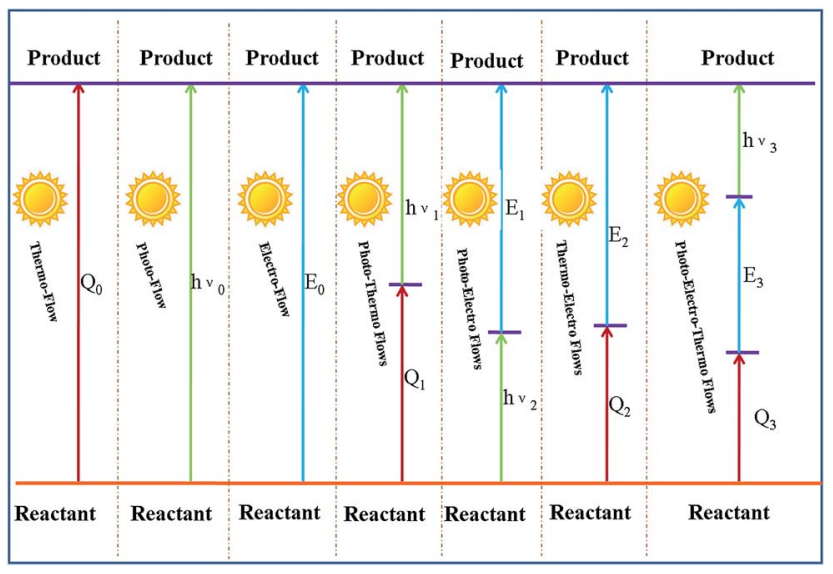

Fig. 2 Energy levels of different flows in the chemical mode.

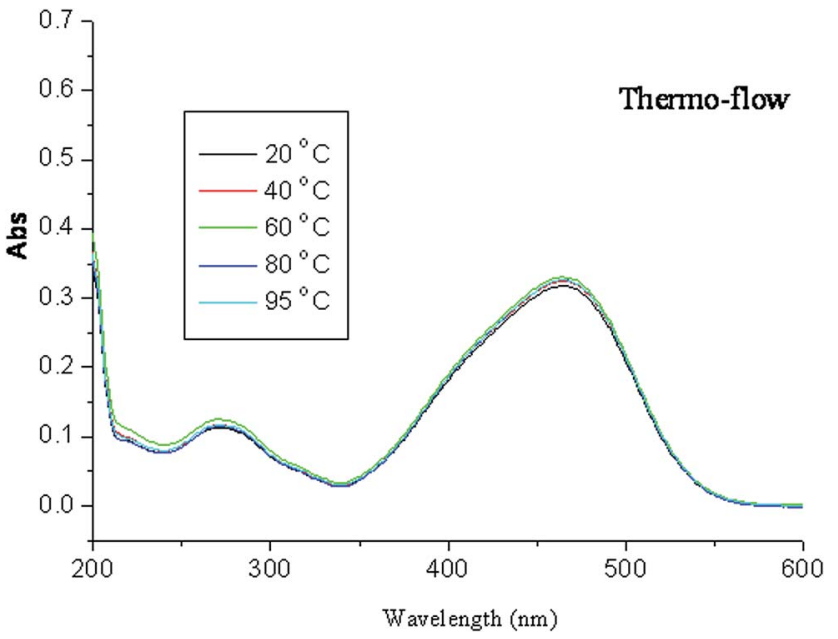

Fig. 3 Oxidation of methyl orange via activation of the single thermoflow.

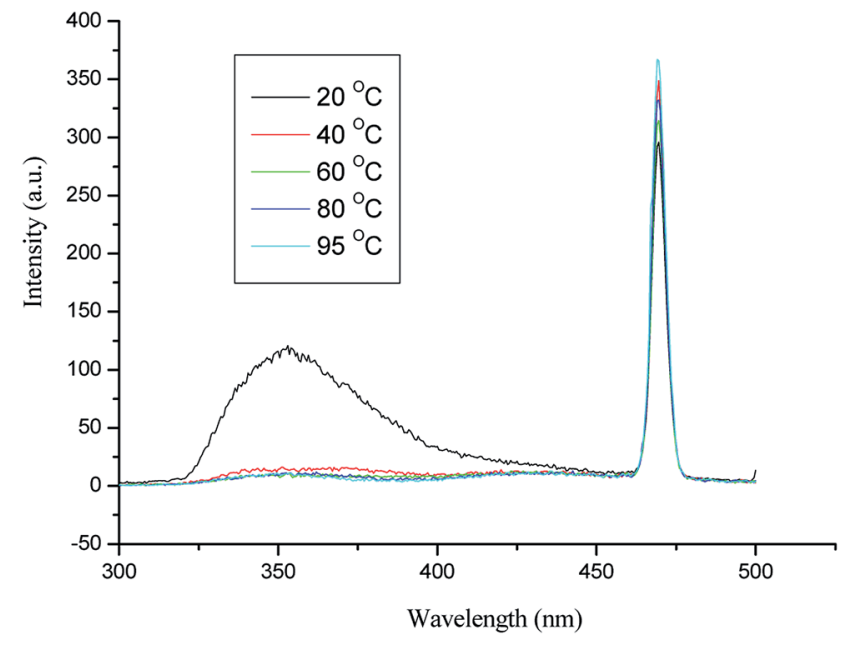

Fig. 4 Fluorescence spectra of methyl orange obtained via activation of the single thermo-flow.

appeared at $474 \mathrm{~nm}$ and $350 \mathrm{~nm}$ when the solution system was excited at $235 \mathrm{~nm}$. The emission peak at $474 \mathrm{~nm}$ changed, whereas that at $350 \mathrm{~nm}$ disappeared with alteration in the reaction temperature; this indicated that heat affected the internal energy structure of molecules. Literature reveals the existence of thermal isomers of azobenzene. ${ }^{36}$ In general, there are two kinds of mechanisms for the existence of thermal isomers: one is from the rotation of the azo bond and the other is the inversion of the $\mathrm{N}-\mathrm{N}-\mathrm{C}$ bond angle. Furthermore, new theoretical results show that the existence of thermal isomers of azobenzene may involve the transition of singlet and triplet; ${ }^{37}$ this causes a change in the molecular energy level. That is, heat makes the methyl orange molecules be in an activation state of high energy, and undergo a further reaction easily.

Fig. 5 shows the measured reaction of azo dye oxidation under the solar photo-flow. The oxidation efficiency can reach $5.13 \%$ and $12.8 \%$, respectively, after oxidation for $30 \mathrm{~min}$ and 

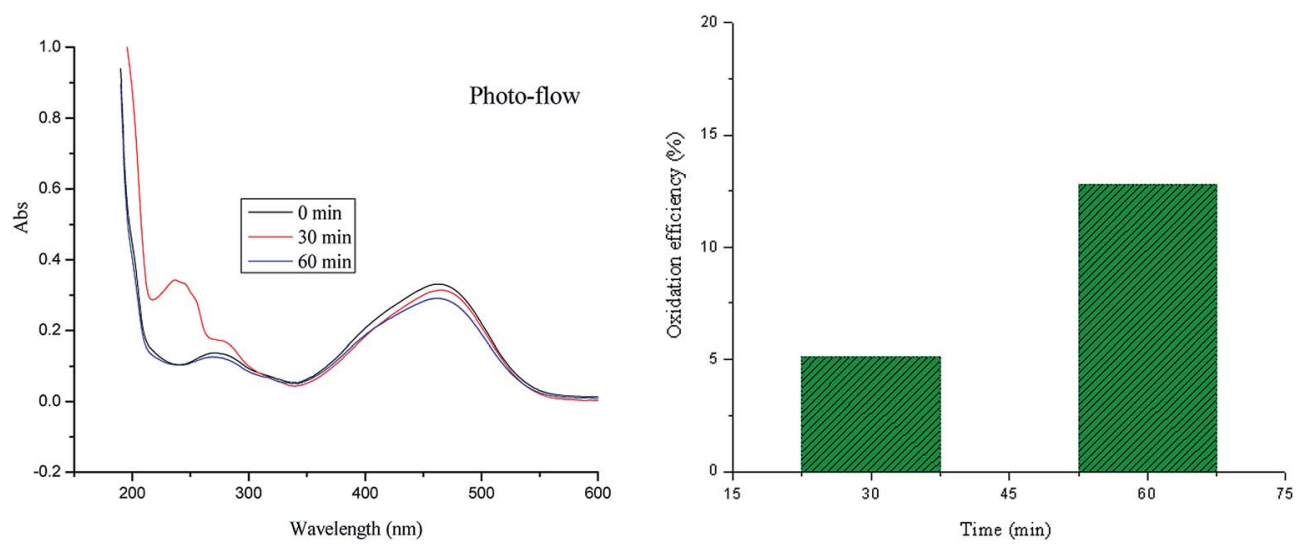

Fig. 5 Oxidation of methyl orange by excitation of single photo-flow.

$60 \mathrm{~min}$ at room temperature. Titanium dioxide is an n-type semiconductor with a band gap of $3.2 \mathrm{eV} \cdot{ }^{38}$ When it is exposed to ultraviolet radiation, electrons gain energy and jump from the valence band to the conduction band; this causes the formation of photo-generated electrons $\left(\mathrm{e}^{-}\right)$. Moreover, photo-generated holes $\left(\mathrm{h}^{+}\right)$form in the valence band. ${ }^{39}$ Therefore, titanium dioxide dispersed in the solution becomes a small short-circuit photochemical battery. The photo-generated electrons on the surface of $\mathrm{TiO}_{2}$ are easily captured by the oxidizing substances in the water phase. ${ }^{40}$ The photo-generated holes $\left(\mathrm{h}^{+}\right)$on the corresponding surface of $\mathrm{TiO}_{2}$ can be used to oxidize organic compounds adsorbed on the surface of $\mathrm{TiO}_{2}$ or water molecules and hydroxyl ions adsorbed on the surface of $\mathrm{TiO}_{2}$ into hydroxyl radicals. Hydroxyl radical can oxidize most organic and inorganic pollutants in water into small inorganic molecules such as carbon dioxide and water. As shown in Fig. 5, methyl orange can be oxidized by adding $\mathrm{TiO}_{2}$ (P25) to the reaction system.

Fig. 6 shows the measured reaction of azo dye oxidation under the solar electro-flow. The oxidation efficiency can reach $24 \%$ and $45 \%$ after oxidation for $30 \mathrm{~min}$ and $60 \mathrm{~min}$ at room temperature, respectively. On the surface of $\mathrm{Pt}$ anode, hydroxyl radical is generated, which can attack the azo molecule, leading to the generation of small inorganic molecules.

\subsection{A synergistic combination of two flows for the STEP-AOP mineralization of dye}

To investigate the coupling effect of solar energy for azo dye oxidation, the oxidation efficiency of two-flows for the STEPAOP mineralization of methyl orange has been studied. For the application of solar thermo-electro flows (Fig. 7), the oxidation efficiency is $79 \%$ at $80{ }^{\circ} \mathrm{C}$ after oxidation for $60 \mathrm{~min}$. Compared with oxidation at $20^{\circ} \mathrm{C}$, for the oxidation at $80^{\circ} \mathrm{C}$, the oxidation efficiency increased by $34 \%$; this indicates that thermal energy improves the electrochemical oxidation process.

On applying solar photo-thermo flows, as shown in Fig. 8, it was obtained that heat energy had little effect on the concentration of methyl orange, which may depend on the reaction rate of adsorption, desorption, migration, and rearrangement at different temperatures on the surface of titanium dioxide.

On the application of solar photo-electro flows, the oxidation efficiency is $26.67 \%$ and $49.56 \%$ after oxidation for $30 \mathrm{~min}$ and $60 \mathrm{~min}$ at room temperature, respectively.

\subsection{A synergistic combination of three flows for the STEP- AOP mineralization of dye}

For the application of solar three flows i.e. photo-electro-thermo flows, the synergistic effects are realized for azo dye oxidation,
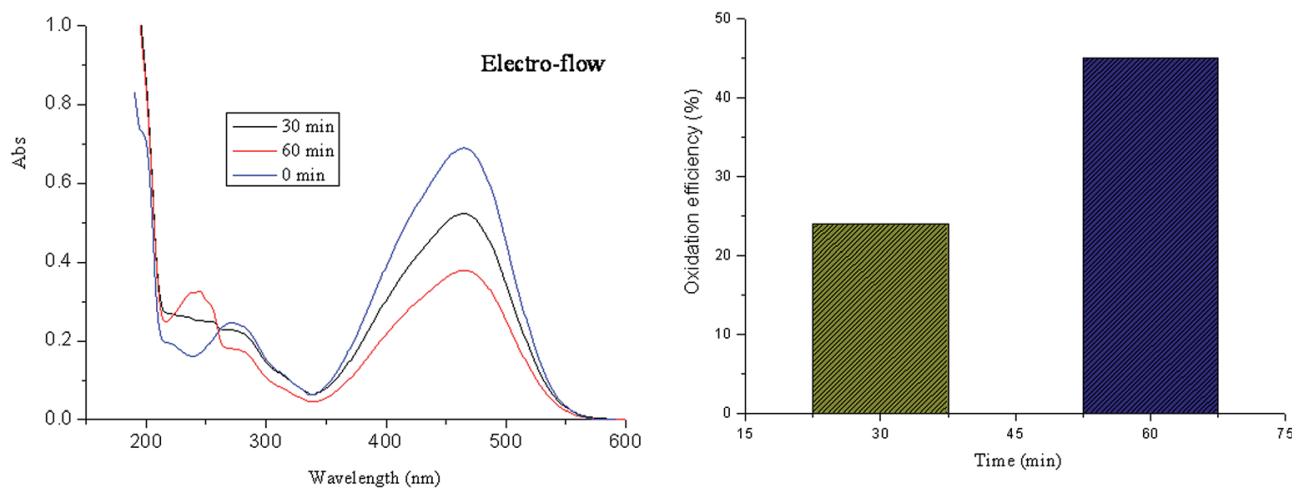

Fig. 6 Oxidation of methyl orange via motivation of single electro-flow. 

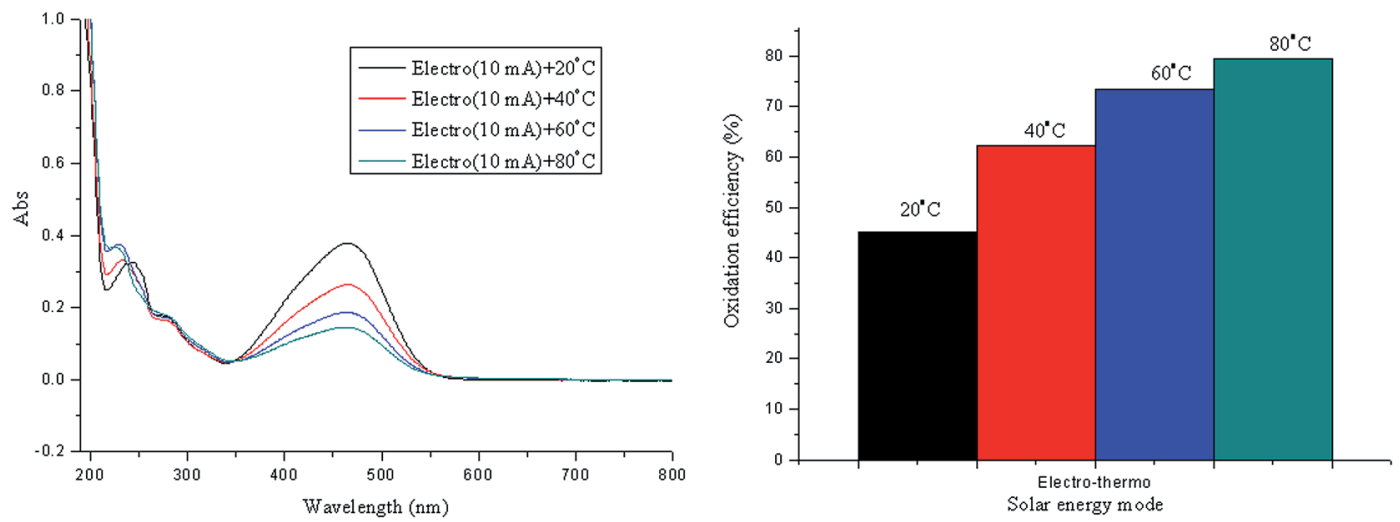

Fig. 7 Oxidation of methyl orange by activation and motivation of the thermo-electro flows.
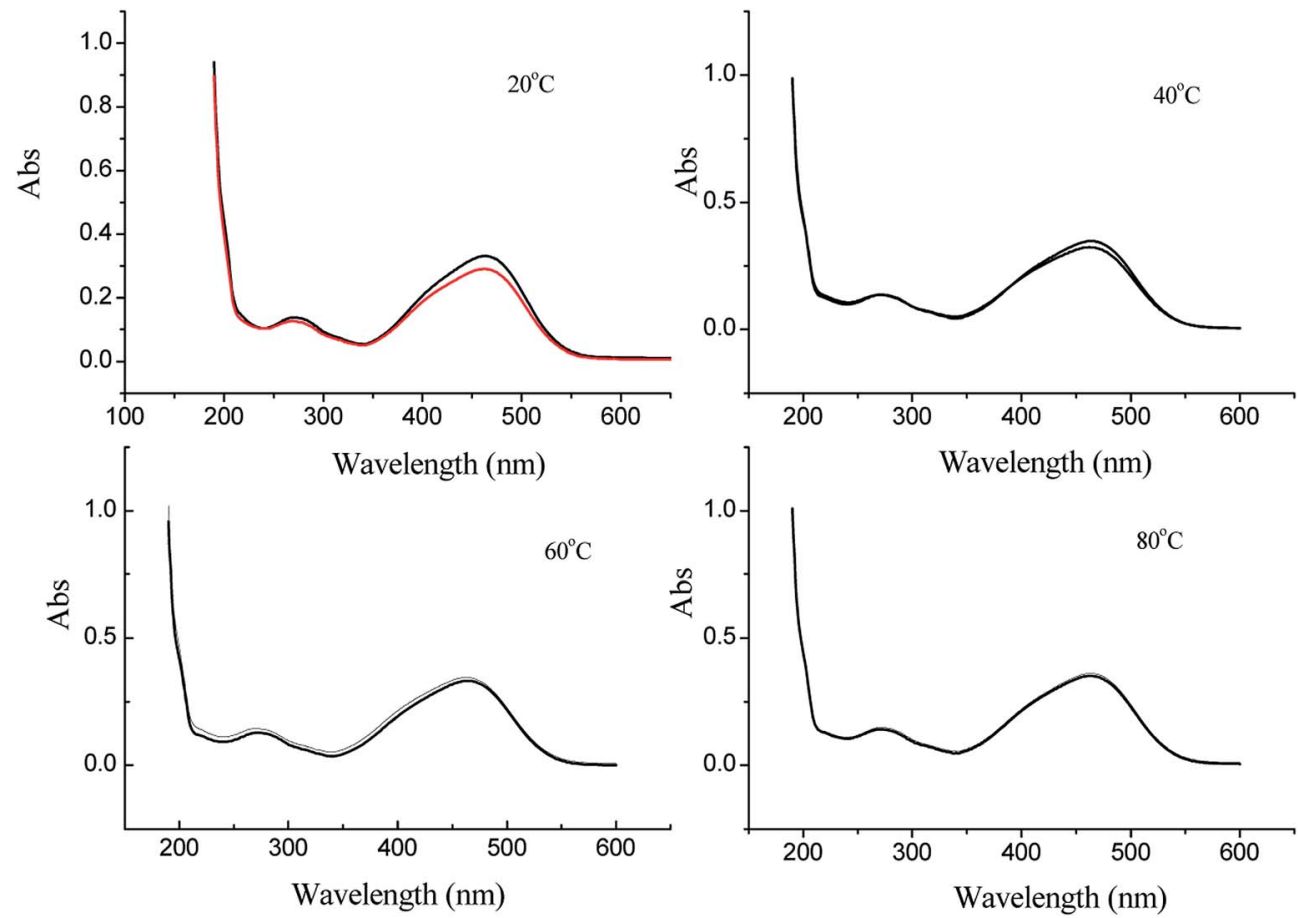

Fig. 8 Oxidation of methyl orange by activation and excitation of photo-thermo flows.

in which the oxidation efficiency is greater than that of the corresponding single flow or two flows. As shown in Fig. 10, the oxidation efficiency is $54.35 \%, 67.25 \%, 76.95 \%$, and $81.88 \%$ at of $20^{\circ} \mathrm{C}, 40^{\circ} \mathrm{C}, 60^{\circ} \mathrm{C}$, and $80^{\circ} \mathrm{C}$, respectively.

The oxidation process of methyl orange indicates that molecular conjugate chains are gradually shortened, ${ }^{41,42}$ which can be reflected in the UV spectrum. The oxidation of methyl orange typically involves the cleavage of the azo bond, the breakdown of the benzene ring, and the formation of small inorganic molecules; these steps are described as decolorization, degradation, and mineralization in this study. Based on these three forms, UV spectra of methyl orange oxidation from $200 \mathrm{~nm}$ to $600 \mathrm{~nm}$ can be divided into three sectors (Fig. 11). Sector I refers to a wavelength range from $350 \mathrm{~nm}$ to $600 \mathrm{~nm}$, which reflects the process of decolorization. Sector II refers to a wavelength range from $265 \mathrm{~nm}$ to $350 \mathrm{~nm}$, which reflects the process of degradation. Sector III refers to a wavelength range from $200 \mathrm{~nm}$ to $265 \mathrm{~nm}$, which reflects the process of mineralization.

As far as single-flow solar energy is concerned, decolorization occurs in all flows, whereas degradation occurs only in electro-flow, which can be seen in Fig. 3, 5, and 6. Relatively, the decolorization effect of electro-flow is also more obvious. For two-flow solar energy, thermo-electro flows present an excellent oxidation effect in the process of decolorization and degradation. Compared to a single photo-flow, photo-electro flows present improvement in the process of decolorization and degradation; however, mineralization is not reflected in sector III, as shown in Fig. 9. The photo-thermo flows present a tiny gradient change with respect to decolorization and degradation. 

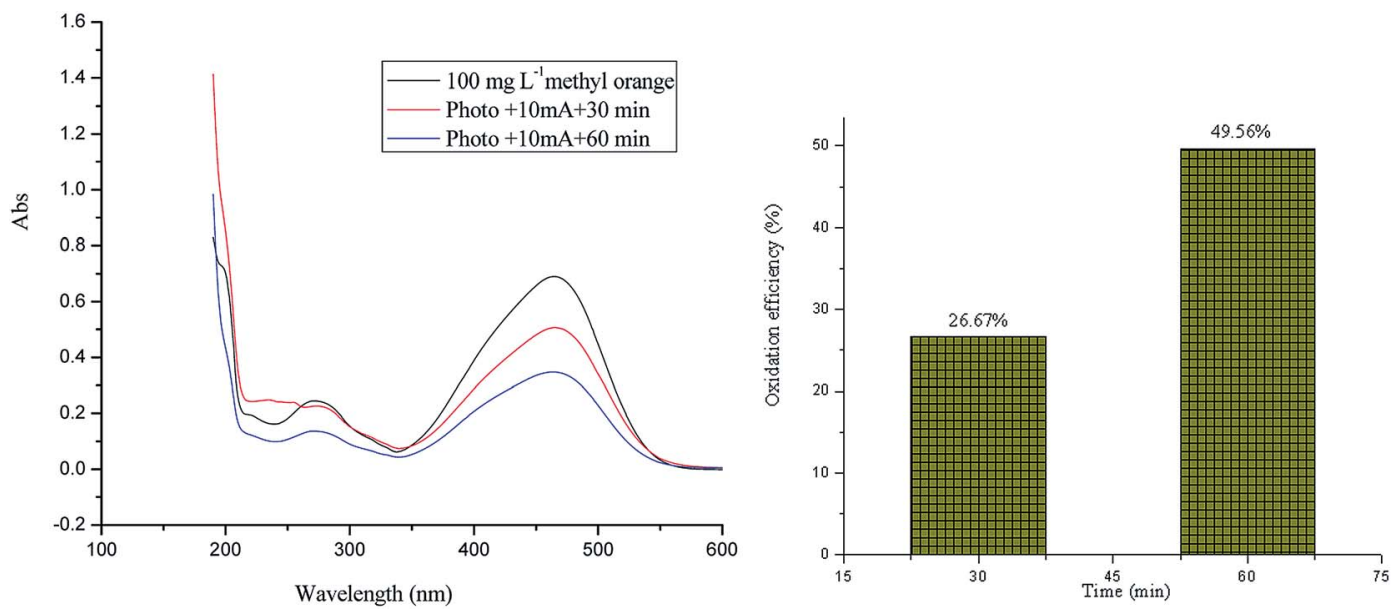

Fig. 9 Oxidation of methyl orange by excitation and motivation of photo-electro flows.
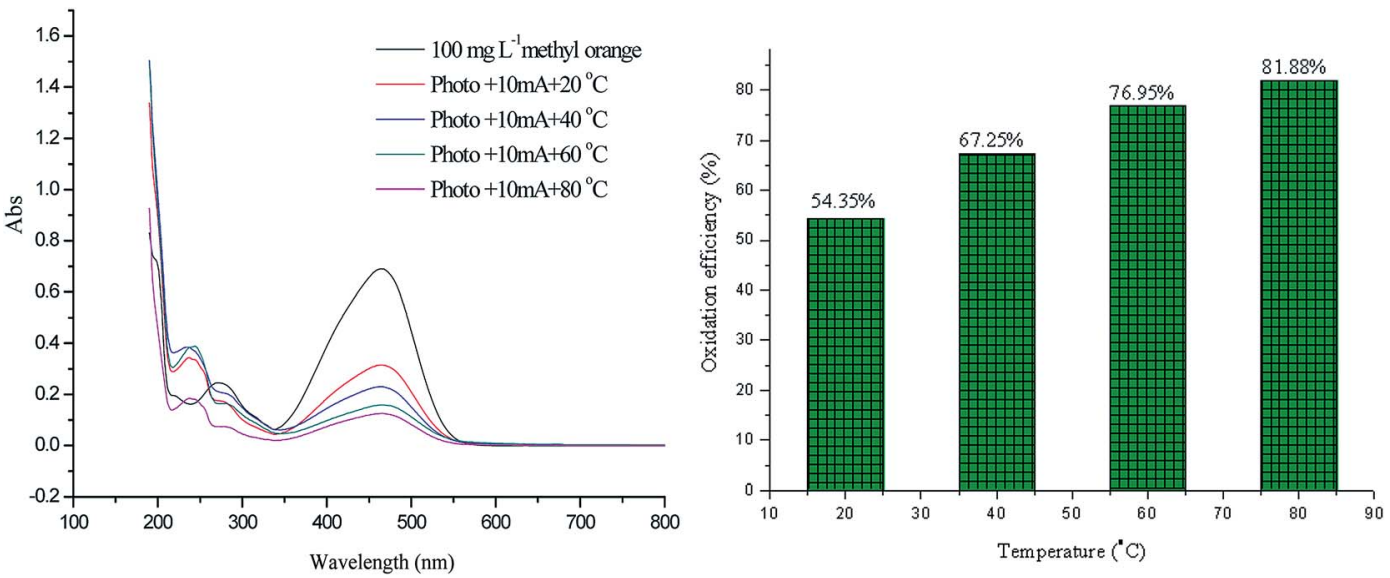

Fig. 10 Oxidation of methyl orange by the action of photo-electro-thermo flows.

For the photo-electro-thermo flows, not only decolorization of sectorland degradation of sector II have been significantly changed, but also mineralization of sector III has been

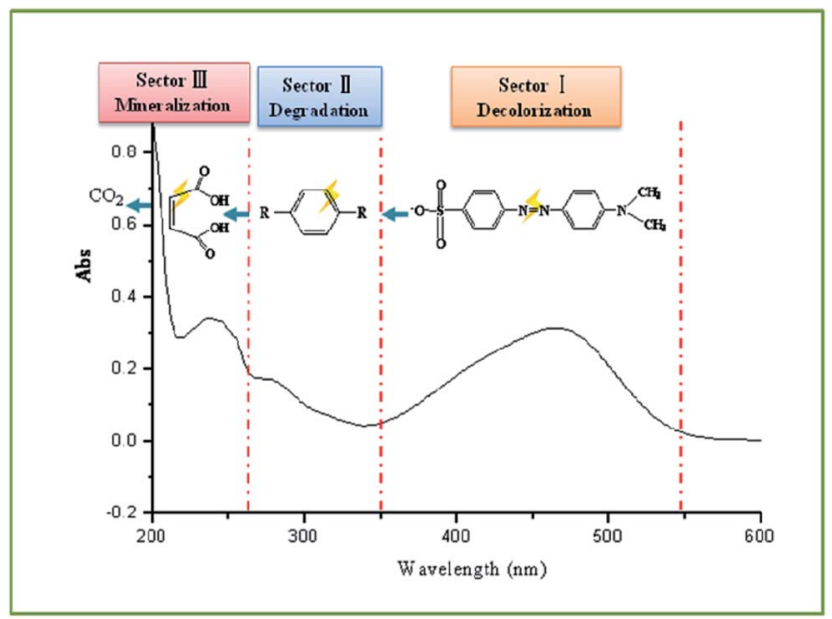

Fig. 11 Oxidation steps of methyl orange reflected in the UV spectrum. observed. As shown in Fig. 10, the absorption peak intensity in sector III increases initially with temperature, which means an increase in conjugated small molecules, and then sharply decreases, which means the breakage of small conjugated molecules, i.e. the mineralization of small organic molecules. Only when photo-flow is added to the conversion system, full mineralization of methyl orange can be realized within $60 \mathrm{~min}$, which indicates photocatalytic oxidation of electrochemical products. Therefore, the joint application of thermo-flow, photo-flow, and electro-flow ensures the realization of full mineralization of the azo dye (Table 1).

\section{Mechanism and kinetic model}

Under the application of solar three-flow driven STEP-AOP mineralization, the oxidation of methyl orange depends on the presence of heterogeneous hydroxyl radical, which can nonselectively oxidize most organic pollutants. ${ }^{43}$ Most hydroxyl radicals are generated from the cracking of water molecules on the surface of the anode and $\mathrm{TiO}_{2},{ }^{44}$ and a small part of them originate from the cleavage of organic molecules. Hydroxyl 
Table 1 Synergistic effects of three flows from solar energy ${ }^{a}$

\begin{tabular}{llll}
\hline & $\begin{array}{l}\text { Decolorization } \\
\text { demo in UV } \\
\text { Field }\end{array}$ & $\begin{array}{l}\text { Degradation } \\
\text { demo in UV } \\
\text { (sector II) }\end{array}$ & $\begin{array}{l}\text { Mineralization } \\
\text { demo in UV } \\
\text { (sector III) }\end{array}$ \\
\hline Thermo-flow & + & 0 & 0 \\
Electro-flow & +++ & +++ & 0 \\
Photo-flow & ++ & + & 0 \\
Thermo-electro flows & ++++ & ++++ & 0 \\
Photo-thermo flows & + & + & 0 \\
Photo-electro flows & ++ & ++ & 0 \\
Photo-thermo-electro & +++++ & +++++ & +++ \\
flows & & & \\
a Note: "+" positive effect, “0” little effect. &
\end{tabular}

radicals were continuously passed on and attacked the molecular chain of methyl orange, leading to the cleavage of the azo bond, the breakdown of the benzene ring, and formation of small molecules until complete mineralization (Fig. 12).

Methyl orange and its oxidized products were monitored using HPLC. With the progress of the reaction, new peaks were detected. The peaks at $0.636 \mathrm{~min}$ and $0.961 \mathrm{~min}$ correspond to oxalic acid and maleic acid, respectively. The peak at $2.061 \mathrm{~min}$ corresponds to methyl orange. The peak at $3.196 \mathrm{~min}$ corresponds to hydroquinone and that at $3.440 \mathrm{~min}$ corresponds to aniline. The peak at 4.393 is attributed to benzoquinone, and the peak at $4.759 \mathrm{~min}$ is attributed to para benzoquinone. Gas chromatography also determined hydrogen and carbon dioxide. These new substances provide the basis for our study on the degradation pathway of methyl orange (Fig. 13).

The model of solar three-flow driven STEP-AOP mineralization of dye enhances solar utilization because of the coapplication of the three flows. The unique role and combined effect of the three flows achieve a coupling and matching integration of the three chemistries for increased chemical efficiency and selectivity. Compared with traditional

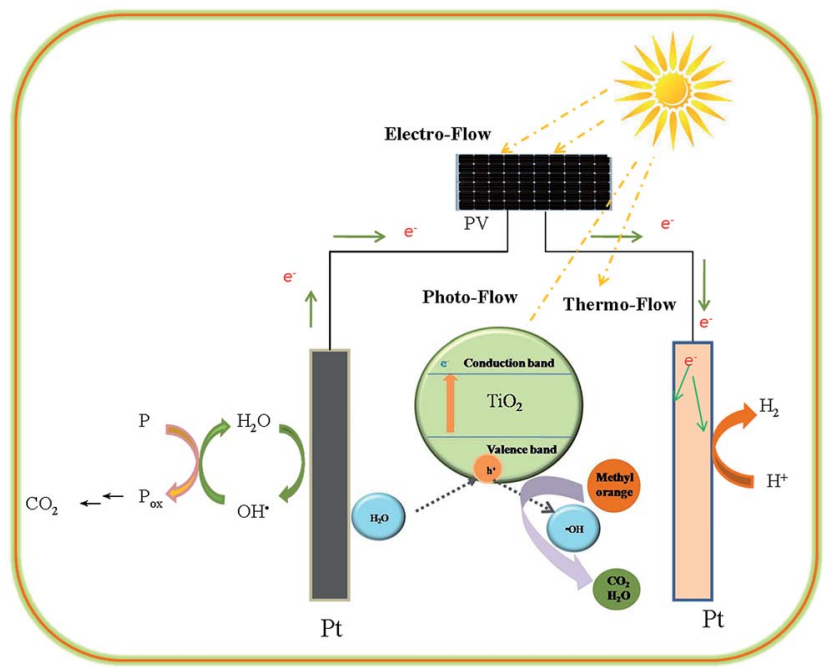

Fig. 12 Schematic of the mode and route of three-flow driven STEPAOP mineralization of dye.

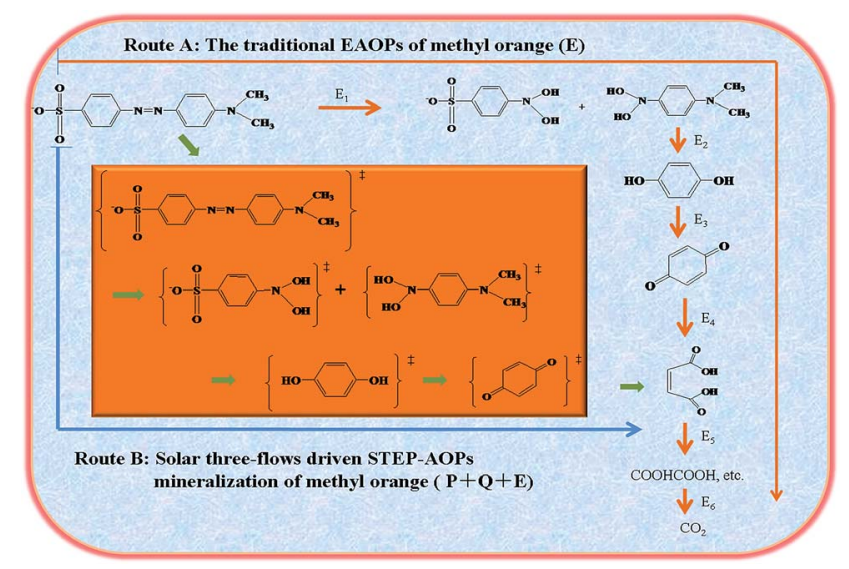

Fig. 13 Proposed reaction pathways and mechanisms of the threeflow driven STEP-AOP mineralization of dyes in comparison with traditional EAOPS.

electrochemical advanced oxidation processes, i.e. EAOPs, the solar three-flow driven STEP-AOP mineralization of dye make full use of solar energy. As shown in Fig. 13, there are two routes for methyl orange oxidation. Route A shows the traditional EAOPs, in which methyl orange requires higher potential to get oxidized into carbon dioxide. Route B shows thermoelectrochemistry plus photocatalysis path. In route $\mathrm{B}$, methyl orange gains photo energy $(P)$, thermo energy $(Q)$, and electro energy $(E)$ from solar energy, and is lifted in an activated state of high energy. Then, it is easily degraded and fully mineralized into $\mathrm{CO}_{2}$ under the synergistic action of thermoactivation, electrooxidation, and photocatalysis.

The oxidation of methyl orange is proven to be complicated with many intermediates and processes. The reaction equation for the final product $\left(\mathrm{CO}_{2}\right)$ is simply expressed without considering the intermediate processes.

The oxidation of methyl orange is composed of the following eqn (1)-(4).

Oxidation reaction:

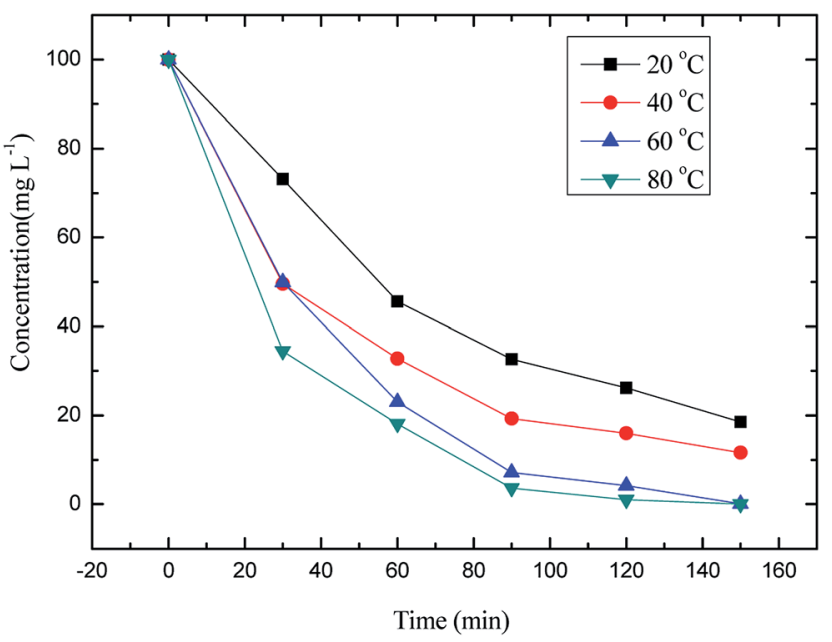

Fig. 14 Concentration changes in methyl orange. 


$$
\begin{gathered}
2 \mathrm{H}_{2} \mathrm{O}(\mathrm{l}) \rightarrow 2^{\circ} \mathrm{OH}+2 \mathrm{H}^{+}+2 \mathrm{e}^{-} \\
\mathrm{C}_{14} \mathrm{H}_{14} \mathrm{~N}_{3} \mathrm{SO}_{3} \mathrm{Na}(\mathrm{l})+38^{\circ} \mathrm{OH}(\mathrm{l}) \rightarrow 14 \mathrm{CO}_{2}(\mathrm{~g})+3 \mathrm{HNO}_{3}(\mathrm{l}) \\
+1 / 2 \mathrm{Na}_{2} \mathrm{SO}_{4}(\mathrm{l})+1 / 2 \mathrm{H}_{2} \mathrm{SO}_{4}(\mathrm{l})+48 \mathrm{H}^{+}(\mathrm{l})+48 \mathrm{e}
\end{gathered}
$$

Reduction reaction:

$$
86 \mathrm{H}^{+}(\mathrm{l})+86 \mathrm{e}^{-} \rightarrow 43 \mathrm{H}_{2}(\mathrm{~g})
$$

Overall reaction:

$$
\begin{aligned}
\mathrm{C}_{14} \mathrm{H}_{14} \mathrm{~N}_{3} \mathrm{SO}_{3} \mathrm{Na}(\mathrm{l})+38 \mathrm{H}_{2} \mathrm{O}(\mathrm{l}) \rightarrow 14 \mathrm{CO}_{2}(\mathrm{~g})+43 \mathrm{H}_{2}(\mathrm{~g}) \\
+3 \mathrm{HNO}_{3}(\mathrm{l})+1 / 2 \mathrm{Na}_{2} \mathrm{SO}_{4}(\mathrm{l})+1 / 2 \mathrm{H}_{2} \mathrm{SO}_{4}(\mathrm{l})
\end{aligned}
$$

According to the chemical kinetic theory and definition of chemical reaction rate, the degradation rate of methyl orange can be described by eqn (5):

Table 2 Oxidation rate at different temperatures

\begin{tabular}{lllll}
\hline & \multicolumn{4}{l}{ Reaction rate $\left(\mathrm{mg} \mathrm{L}^{-1} \cdot \mathrm{min}^{-1}\right)$} \\
\cline { 2 - 5 } Time $/ \mathrm{min}$ & $20{ }^{\circ} \mathrm{C}$ & $40{ }^{\circ} \mathrm{C}$ & $60{ }^{\circ} \mathrm{C}$ & $80{ }^{\circ} \mathrm{C}$ \\
\hline 0 & 0.894 & 1.68167 & 1.66933 & 2.18367 \\
30 & 0.90583 & 1.12083 & 1.28267 & 1.36467 \\
60 & 0.67533 & 0.504 & 0.71333 & 0.51397 \\
90 & 0.3235 & 0.28 & 0.31417 & 0.285 \\
120 & 0.23517 & 0.129 & 0.117 & 0.06053 \\
150 & 0.25633 & 0.146 & 0.13633 & 0.03333
\end{tabular}

$$
r=k\left[\mathrm{C}_{14} \mathrm{H}_{14} \mathrm{~N}_{3} \mathrm{SO}_{3} \mathrm{Na}\right]^{n} \cdot\left[\mathrm{H}_{2} \mathrm{O}\right]^{m}
$$

In our experiments, the concentration of methyl orange was generally $100 \mathrm{mg} \mathrm{L}^{-1}$. Relative to the concentration of methyl orange, the water concentration was infinite. The concentration variation of water $\left(\left[\mathrm{H}_{2} \mathrm{O}\right]\right)$ can be regarded as constant. $k\left[\mathrm{H}_{2} \mathrm{O}\right]^{m}$ can be expressed as $k^{\prime}$. The rate equation can be simplified as follows:

$$
r=k^{\prime}\left[\mathrm{C}_{14} \mathrm{H}_{14} \mathrm{~N}_{3} \mathrm{SO}_{3} \mathrm{Na}\right]^{n}=-\mathrm{d}\left[\mathrm{C}_{14} \mathrm{H}_{14} \mathrm{~N}_{3} \mathrm{SO}_{3} \mathrm{Na}\right] / \mathrm{d} t
$$

where $r$ is the reaction rate, $t$ is the reaction time, $k^{\prime}$ is the kinetic constant of this reaction, and $n$ is the order of this reaction.

Under different temperature conditions, the changes in the curves of methyl orange concentration with time are shown in Fig. 14.

The absolute value of the curves slope in Fig. 14 provided the reaction rate under the used condition, which is shown in Table 2.

By eqn (6), it is well known that the determination of the reaction order is the crux of the establishment of a dynamic equation.

Non-linear regression can be used to obtain determination coefficient, sum of residual squares, and standard errors of the kinetic constants. The results are shown in Fig. 15; thus, the rate equation of methyl orange oxidation can be described.

As shown in Fig. 15, the oxidation of methyl orange follows different order kinetics with the eventual conversion of methyl
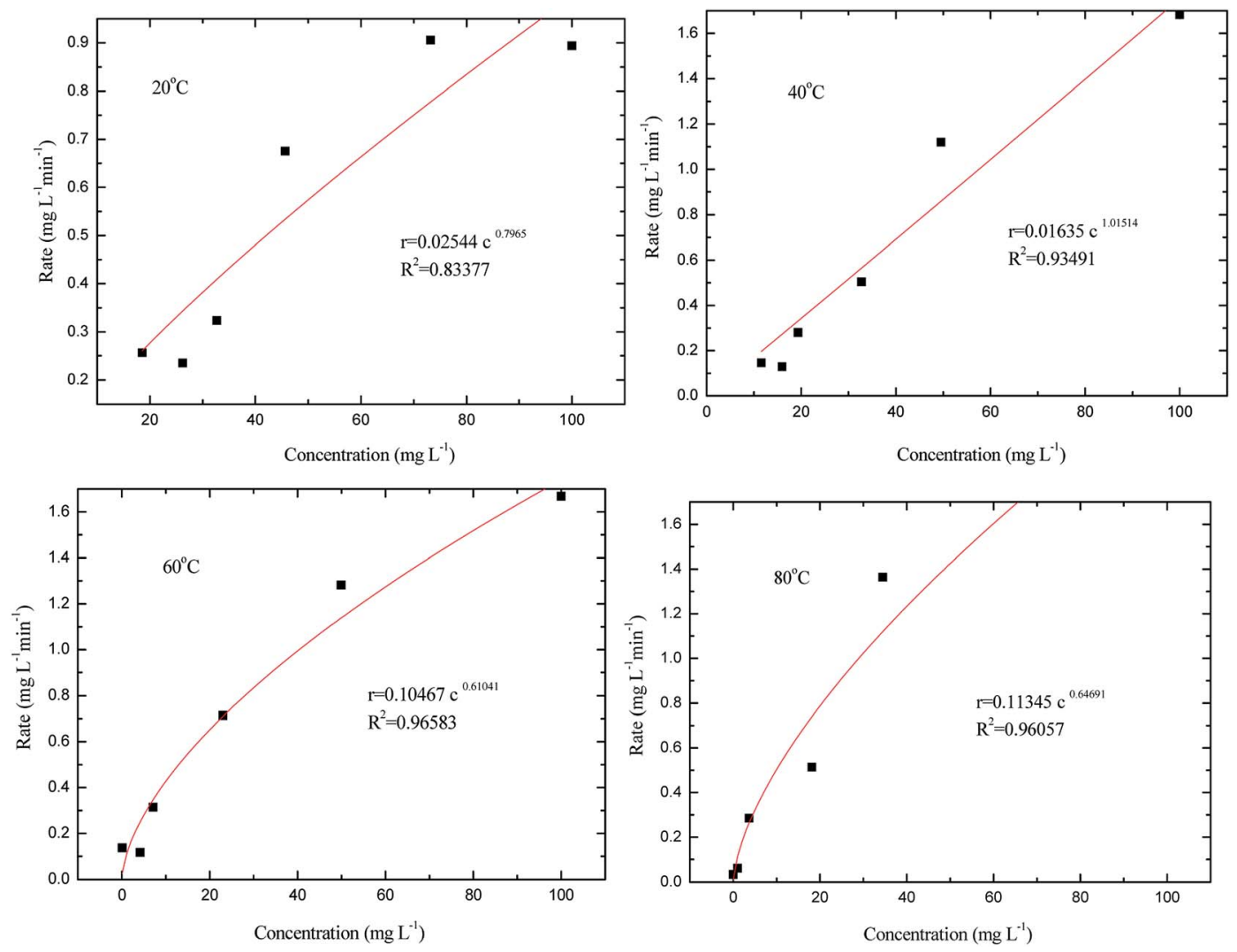

Fig. 15 Rate equation of STEP-AOPs of methyl orange at different temperatures. 
orange carbon into $\mathrm{CO}_{2}$. Since the oxidation of methyl orange is a typical overall reaction consisting of many elementary reactions, the changes in the rate equation indicate that the oxidation follows different mechanisms at different temperatures.

\section{Conclusion}

In summary, a synergistic combination of three flows from solar energy has been successfully constructed and used for the mineralization of an azo dye in wastewater. On activation by the single thermo-flow, the solar heat enables the methyl orange molecules are lifted in an activated state of high energy, highly in favor of the oxidation in succession. On excitation by the single photo-flow, the efficiency of photocatalytic oxidation reached $12.8 \%$ after reaction for $60 \mathrm{~min}$ at room temperature. On motivation by single electro-flow, the efficiency of electrochemical oxidation reached $45 \%$ after $60 \mathrm{~min}$ reaction at room temperature. For the application of solar three flows, the efficiencies of the three-flow STEP-AOPs reached up to $54.35 \%, 67.25 \%, 76.95 \%$, and $81.88 \%$ after $60 \mathrm{~min}$ at $20{ }^{\circ} \mathrm{C}, 40{ }^{\circ} \mathrm{C}, 60{ }^{\circ} \mathrm{C}$, and $80{ }^{\circ} \mathrm{C}$, respectively. In particular, the addition of photo-flow enhanced the performances of the system, which realized full mineralization of methyl orange within $60 \mathrm{~min}$. The oxidized products, such as oxalic acid, maleic acid, hydroquinone, aniline, benzoquinone, and para benzoquinone, were identified by HPLC. Hydrogen and carbon dioxide were determined by gas chromatography. In addition, the oxidation of methyl orange follows different order kinetics with the eventual conversion of methyl orange carbon into $\mathrm{CO}_{2}$. It has been shown that threeflow STEP-AOPs achieved excellent operation with high solar utilization and efficient and selective oxidation.

\section{Acknowledgements}

This work was financially supported by the National Nature Science Foundation of China (NSFC Project No. 21376049) and Young Innovative Talent Training Program of Heilongjiang Province (UNPYSCT Project No.2016083) and partly supported by the Science Foundation for Creative Research Groups of the Heilongjiang Higher Education Institutes of China (No.2013TD004).

\section{References}

1 European Parliament and Council of the European Union, Off. J. Eur. Communities: Legis., 2000, L327, 1-3.

2 R. Salazar, E. Brillas and I. Sirés, Finding the Best $\mathrm{Fe}^{2+} / \mathrm{Cu}^{2+}$ Combination for the Solar Photoelectro-Fenton Treatment of Simulated Wastewater Containing the Industrial Textile Dye Disperse Blue 3, Appl. Catal., B, 2012, 115-116, 107-116.

3 T. Robinson, G. McMullan, R. Marchant and P. Nigam, Remediation of Dyes in Textile Effluent: A Critical Review on Current Treatment Technologies with a Proposed Alternative, Bioresour. Technol., 2001, 77, 247-255.

4 C. A. Martínez-Huitle and E. Brillas, Decontamination of Wastewaters Containing Synthetic Organic Dyes by
Electrochemical Methods: A General Review, Appl. Catal., $B, 2009,87,105-145$.

5 M. Solís, A. Solís, H. I. Pérez, N. Manjarrez and M. Flores, Microbial Decolouration of Azo Dyes: A Review, Process Biochem., 2012, 47, 1723-1748.

6 F. Fu and T. Viraraghavan, Fungal Decolorization of Dye Wastewaters: A Review, Bioresour. Technol., 2001, 79, 251262.

7 C. C. Hsu, Y. T. Wang, A. Yabushita, C. W. Luo, Y. N. Hsiao, S. H. Lin and T. Kobayashi, Environment-Dependent Ultrafast Photoisomerization Dynamics in Azo Dye, J. Phys. Chem. A, 2011, 115, 11508-11514.

8 E. Razo-Flores, M. Luijten, B. A. Donlon, G. Lettinga and J. A. Field, Complete Biodegradation of the Azo Dye Azodisalicylate under Anaerobic Conditions, Environ. Sci. Technol., 1997, 31, 2098-2103.

9 A. Roy, B. Adhikari and S. B. Majumder, Equilibrium, Kinetic, and Thermodynamic Studies of Azo Dye Adsorption from Aqueous Solution by Chemically Modified Lignocellulosic Jute Fiber, Ind. Eng. Chem. Res., 2013, 52, 6502-6512.

10 A. D. Bokare, R. C. Chikate, C. V. Rode and K. M. Paknikar, Effect of Surface Chemistry of Fe-Ni Nanoparticles on Mechanistic Pathways of Azo Dye Degradation, Environ. Sci. Technol., 2007, 41, 7437-7443.

11 J. Mathieu-Denoncourt, C. J. Martyniuk, S. R. de Solla, V. K. Balakrishnan and V. S. Langlois, Sediment Contaminated with the Azo Dye Disperse Yellow 7 Alters Cellular Stress- and Androgen-Related Transcription in Silurana tropicalis Larvae, Environ. Sci. Technol., 2014, 48, 2952-2961.

12 E. Forgacs, T. Cserhati and G. Oros, Removal of Synthetic Dyes from Wastewaters: A Review, Environ. Int., 2004, 30, 953-971.

13 A. B. dos Santos, F. J. Cervantes and J. B. van Lier, Review Paper on Current Technologies for Decolourisation of Textile Wastewaters: Perspectives for Anaerobic Biotechnology, Bioresour. Technol., 2007, 98, 2369-2385.

14 M. Klavarioti, D. Mantzavinos and D. Kassinos, Removal of Residual Pharmaceuticals from Aqueous systems by Advanced Oxidation Processes, Environ. Int., 2009, 35, 402417.

15 N. Shang and Y. Yu, The Biotoxicity and Color Formation Results from Ozonation of Wastewaters Containing Phenol and Aniline, J. Environ. Sci. Health, Part A: Toxic/Hazard. Subst. Environ. Eng., 2001, 36, 383-389.

16 S. K. Gupta, M. K. Nayunigari, R. Misra, F. A. Ansari, D. D. Dionysiou, A. Maity and F. Bux, Synthesis and Performance Evaluation of a New Polymeric Composite for the Treatment of Textile Wastewater, Ind. Eng. Chem. Res., 2016, 55, 13-20.

17 J. Choi and J. Chung, Reuse of Semiconductor Wastewater Using Reverse Osmosis and Metal-Immobilized CatalystBased Advanced Oxidation Process, Ind. Eng. Chem. Res., 2014, 53, 11167-11175.

18 Y. Y. Zhao, J. M. Boyd, M. Woodbeck, R. C. Andrews, F. Qin, S. E. Hrudey, et al., Formation of $N$-Nitrosamines from 
Eleven Disinfection Treatments of Seven Different Surface Waters, Environ. Sci. Technol., 2008, 42, 4857-4862.

19 E. J. Rosenfeldt and K. G. Linden, Degradation of Endocrine Disrupting Chemicals Bisphenol A, Ethinyl Estradiol, and Estradiol during UV Photolysis and Advanced Oxidation Processes, Environ. Sci. Technol., 2004, 38, 5476-5483.

20 M. O. Buffle and U. Gunten, Phenols and Amine Induced $\mathrm{HO}^{•}$ Generation during the Initial Phase of Natural Water Ozonation, Environ. Sci. Technol., 2006, 40, 3057-3063.

21 D. Santoro, M. Raisee, M. Moghaddami, J. Ducoste, M. Sasges, L. Liberti and M. Notarnicola, Modeling Hydroxyl Radical Distribution and Trialkyl Phosphates Oxidation in UV- $\mathrm{H}_{2} \mathrm{O}_{2}$ Photoreactors Using Computational Fluid Dynamics, Environ. Sci. Technol., 2010, 44, 6233-6241.

22 M. K. Dail and S. P. Mezyk, Hydroxyl-Radical-Induced Degradative Oxidation of $\beta$-Lactam Antibiotics in Water: Absolute Rate Constant Measurements, J. Phys. Chem. A, 2010, 114, 8391-8395.

23 O. S. Keen and K. G. Linden, Re-Engineering an Artificial Sweetener: Transforming Sucralose Residuals in Water via Advanced Oxidation, Environ. Sci. Technol., 2013, 47, 6799-6805.

24 J. M. Barazesh, T. Hennebel, J. T. Jasper and D. L. Sedlak, Modular Advanced Oxidation Process Enabled by Cathodic Hydrogen Peroxide Production, Environ. Sci. Technol., 2015, 49, 7391-7399.

25 W. Chu, N. Gao, D. Yin, S. W. Krasnerand and W. A. Mitch, Impact of $\mathrm{UV} / \mathrm{H}_{2} \mathrm{O}_{2}$ Pre-Oxidation on the Formation of Haloacetamides and Other Nitrogenous Disinfection Byproducts during Chlorination, Environ. Sci. Technol., 2014, 48, 12190-12198.

26 R. Oulton, J. P. Haase, S. Kaalberg, C. T. Redmond, M. J. Nalbandian and D. M. Cwiertny, Hydroxyl Radical Formation during Ozonation of Multiwalled Carbon Nanotubes: Performance Optimization and Demonstration of a Reactive CNT Filter, Environ. Sci. Technol., 2015, 49, 3687-3697.

27 S. Licht, B. H. Wang, S. Ghosh, H. Ayub, D. Jiang and J. Ganely, A New Solar Carbon Capture Process: Solar Thermal Electrochemical Photo (STEP) Carbon Capture, $J$. Phys. Chem. Lett., 2010, 1, 2363-2365.

28 S. Licht, B. H. Wang and H. J. Wu, STEP-A Solar Chemical Process to End Anthropogenic Global Warming. II: Experimental Results, J. Phys. Chem. C, 2011, 115, 11803-11821.

29 B. H. Wang, H. J. Wu, G. Zhang and S. Licht, STEP Wastewater Treatment: A Solar Thermal Electrochemical Process for Pollutant Oxidation, ChemSusChem, 2012, 5, 2000-2010.

30 B. H. Wang, Y. Hu and H. J. Wu, Solar Driven Thermal Electrochemical Process (STEP) Wastewater Treatment with Synergistic Production of Hydrogen, ECS Electrochem. Lett., 2013, 2, H34-H36.

31 S. Licht, B. C. Cui, B. H. Wang, F. F. Li, J. Lau and S. Z. Liu, Ammonia Synthesis by $\mathrm{N}_{2}$ and Steam Electrolysis in Molten Hydroxide Suspensions of Nanoscale $\mathrm{Fe}_{2} \mathrm{O}_{3}$, Science, 2014, 345, 637-640.

32 C. H. Nie, N. Shao, B. H. Wang, D. D. Yuan, X. Sui and H. J. Wu, Fully Solar-Driven Thermo- and Electrochemistry for Advanced Oxidation Processes (STEP-AOPs) of 2Nitrophenol Wastewater, Chemosphere, 2016, 154, 604-612.

33 C. H. Nie, L. Xu, D. Gu, G. S. Cao, R. X. Yuan and B. H. Wang, Toward Efficient Demulsification of Produced Water in Oilfields: Solar STEP Directional Degradation of Polymer on Interfacial Film of Emulsions, Energy Fuels, 2016, 30, 9686-9692.

34 C. J. Shi, X. L. Dong, J. W. Wang, X. Y. Wang, H. C. Ma and X. F. Zhang, Interfacial Defect Engineering over Fusiform Bismuth Vanadate Photocatalyst Enables to Excellent Solar-to-Chemical Energy Coupling, RSC Adv., 2017, 7, 26717-26721.

35 Y. J. Zhu, H. Y. Wang, B. H. Wang, X. L. Liu, H. J. Wu and S. Licht, Solar Thermoelectric Field plus Photocatalysis for Efficient Organic Synthesis Exemplified by Toluene to Benzoic Acid, Appl. Catal., B, 2016, 193, 151-159.

36 J. Henzl, M. Mehlhorn, H. Gawronski, K. H. Rieder and K. Morgenstern, Reversible cis-trans Isomerization of a Single Azobenzene Molecule, Angew. Chem., Int. Ed., 2006, 45, 603-606.

37 A. Cembran, F. Bernadi, M. Garavelli, L. Gagliardi and G. Orlandi, On the Mechanism of the Cis-Trans Isomerization in the Lowest Electronic States of Azobenzene: $\mathrm{S}_{0}, \mathrm{~S}_{1}$, and $\mathrm{T}_{1}, \mathrm{~J}$. Am. Chem. Soc., 2004, 126, 3234-3243.

38 G. Colon, M. C. Hidalgo, M. Macias, J. A. Navío and J. M. Doña, Influence of Residual Carbon on the Photocatalytic Activity of $\mathrm{TiO}_{2}$ Samples for Phenol Oxidation, Appl. Catal., B, 2003, 43, 163-173.

39 J. Yao, Y. F. Zhang, Y. W. Wang, M. J. Chen, Y. Huang, J. J. Cao, W. K. Ho and S. C. Lee, Enhanced Photocatalytic Removal of NO over Titania/Hydroxyapatite $\left(\mathrm{TiO}_{2} / \mathrm{HAp}\right)$ Composites with Improved Adsorption and Charge Mobility Ability, RSC Adv., 2017, 7, 24683-24689.

40 L. Gomathi Devi and R. Kavitha, Review on Modified N-TiO for Green Energy Applications under UV/visible Light: Selected Results and Reaction Mechanisms, RSC Adv., 2014, 4, 28265-28299.

41 Z. H. Wang, L. Y. Ai, Y. Huang, J. K. Zhang, S. T. Li, J. W. Chen and F. Yang, Degradation of Azo Dye with Activated Peroxygens: when Zero-Valent Iron Meets Chloride, RSC Adv., 2017, 7, 30941-30948.

42 Y. N. Liu, X. Zhou, X. Wang, K. Liang, Z. K. Yang, C. C. Shen, M. Imran, S. Sahar and A. W. Xu, Hydrogenation/Oxidation Induced efficient Reversible Color Switching between Methylene Blue and Leuco-methylene Blue, RSC Adv., 2017, 7, 30080-30085.

43 S. Salamat, H. Younesi and N. Bahramifar, Synthesis of Magnetic Core-Shell $\mathrm{Fe}_{3} \mathrm{O}_{4} @ \mathrm{TiO}_{2}$ Nanoparticles from Electric arc Furnace Dust for Photocatalytic Degradation of Steel Mill Wastewater, RSC Adv., 2017, 7, 19391-19405.

44 S. Sankar Boxi and S. Paria, Visible Light Induced Enhanced Photocatalytic Degradation of Organic Pollutants in Aqueous Media using $\mathrm{Ag}$ Doped Hollow $\mathrm{TiO}_{2}$ Nanospheres, RSC Adv., 2015, 5, 37657-37668. 